\title{
STRATEGI INTEGRATED MARKETING COMMUNICATION (IMC) USAHA KEDAI SUSU MOM MILK UNTUK MENARIK MINAT KONSUMEN
}

\author{
Firsto Rozi Kurniawan, Setyowati, Hanifah Ihsaniyati \\ Program Studi Agribisnis Fakultas Pertanian, Universitas Sebelas Maret Surakarta \\ Jl.Ir.Sutami No.36 A Kentingan Surakarta 57126 Telp./Fax (0271) 637457 \\ Email: Kurniawan.tito95@ymail.com
}

\begin{abstract}
This study aims to identify the activities of Integrated Marketing Communications Mom Milk in maintaining marketing activities and consumer interest. Then the strategy could be an alternative strategy for the other businesses in the face of the ASEAN Economic Community. The basic method used in this research is descriptive qualitative method. The location of this study purposively taking case study in Mom Milk considering that Mom Milk is milk bar businesses that are already using some of the activities of integrated marketing communications. Sources of data in this study is a resource, and field observations. Researchers collected data were interviews, records and documentation. Data analysis techniques in this study using an interactive model that consists of three basic components: data reduction, data presentation, and drawing conclusions with the verification to know each Integrated Marketing Communication activities carried out by Mom Milk. The results showed that the marketing communication activities conducted by Mom Milk is linked activities and support each other to inform Mom Milk to consumers. Each activity has functionality ranging from building awareness through radio advertising and magazine advertising, advertising to persuade consumers via the Internet and social media, and to maintain customer loyalty through the provision of incentives and promotion to its customers. Barriers faced by Mom Milk is the number of competitors and people's lifestyles are highly volatile change. However, through creativity and innovation Milk Mom both of products and marketing styles, Mom Milk was never afraid to face it.
\end{abstract}

Keywords: integrated marketing communications, milk barmom milk, barriers, consumer

Abstrak: Penelitian ini bertujuan untuk mengindentifikasi kegiatan Integrated
Marketing Communications kedai Susu Mom Milk dalam mempertahankan kegiatan
pemasaran dan menarik minat konsumen. Kemudian strategi tersebut bisa menjadi
alternatif strategi bagi pelaku usaha lain dalam menghadapi ASEAN Economic
Community. Metode dasar yang digunakan dalam penelitian ini adalah metode
deskriptif kualitatif. Lokasi penelitian ini secara purposive mengambil studi kasus di
Mom Milk dengan pertimbangan bahwa Mom Milk merupakan usaha kedai susu yang
sudah menggunakan beberapa kegiatan komunikasi pemasaran terpadu. Sumber data
pada penelitian ini adalah narasumber, dan observasi lapangan. Peneliti
mengumpulkan data menggunakan teknik wawancara, pencatatan, dan dokumentasi.
Teknik analisis data dalam penelitian ini menggunakan model analisis interaktif yang
terdiri dari 3 komponen pokok yaitu reduksi data, sajian data, dan penarikan simpulan
dengan verifikasinya untuk mengetahui masing-masing kegiatan Integrated Marketing
Communication yang dilakukan oleh Mom Milk.Hasil penelitian menunjukkan bahwa
kegiatan komunikasi pemasaran yang dilakukan oleh Mom Milk merupakan kegiatan
yang saling berhubungan dan saling mendukung untuk menginformasikan Mom Milk
kepada para konsumen. Setiap kegiatan memiliki fungsi mulai dari membangun 
kesadaran melalui iklan radio dan iklan majalah, membujuk konsumen melalui periklanan internet dan media social, dan untuk menjaga loyalitas konsumen melalui pemberian insentif dan promosi kepada para konsumennya. Hambatan yang dihadapi oleh Mom Milk adalah banyaknya pesaing dan gaya hidup masyarakat yang sangat mudah berubah ubah. Namun melalui kreatifitas dan inovasi Mom Milk baik itu dari produk maupun gaya pemasaran, Mom Milk tidak pernah takut untuk menghadapinya.

Kata kunci : Integrated Marketing Communications, kedai susu Mom Milk, hambatan, konsumen

\section{PENDAHULUAN}

Kegiatan pemasaran di era persaingan bisnis sekarang merupakan faktor yang penting untuk mempertahankan dan mengembangkan kehidupan sebuah usaha. Semakin tinggi tingkat persaingan dalam bisnis dewasa ini, mengharuskan pihak manajemen untuk melakukan inovasi dalam menarik minat para pelanggan. Inovasi tersebutlah kemudian yang akan menjadi keunggulan kompetitif sebuah perusahaan. Sebagaimana Kotler (2005) dalam Sangadji dan Sopiah (2013) menjelaskan bahwa selama perusahaan bisa melakukan kegiatan yang lebih baik dari pesaing, perusahaan akan mendapatkan keunggulan kompetitif.

Hifni Alifahmi (2008) dalam bukunya Marketing Communications Orchestra mengatakan "It's not creative unless it sells" yang berarti sebuah inovasi apapun belum akan dikatakan sebuah kreatifitas hingga inovasi tersebut bermanfaat.Demi meningkatkan angka penjualan, perusahaan gencar melakukan promosi baik melalui periklanan maupun alatalat komunikasi pemasaran lainnya seperti humas, pemasaran langsung, penjualan personal, dan promosi penjualan dalam memasarkan produknya. Untuk itu dibutuhkan pendekatan baru dimana alat-alat komunikasi pemasaran bisa berjalan efektif dan terintegrasi.
Salah satunya dengan cara melakukan komunikasi pemasaran terpadu atau Integrated Marketing Communications (IMC).

Produk hasil pertanian sangat beragam dan salah satu yang menjadi kegemaran masyarakat adalah susu sapi. Sebagaimana dalam tabel 1 tentang konsumsi telur dan susu per kapita bahwa dari tahun ke tahun konsumsi susu murni mengalami fluktuasi namun cenderung mengalami peningkatan. Data pada tabel 1 merupakan data mengenai jumlah konsumsi susu per liter per kapita untuk setiap rumah tangga di Indonesia menurut data perhitungan yang dilakukan oleh Survey Sosial Ekonomi Nasional.

Kegemaran masyarakat akan produk susu didukung dengan kandungan gizi dalam susu sapi yang sangat bagus untuk kesehatan. Susu sapi juga merupakan penyempurna gizi masyarakat sesuai dengan konsep gizi seimbang "4 Sehat 5 Sempurna”. Berdasarkan keterangan pada tabel 2 dapat kita ketahui bahwa kandungan susu sapi secara umum lebih baik daripada kandungan susu kambing yang juga sering dijadikan sebagai alternatif dalam mengkonsumsi susu. Nutrisi penting seperti salah satunya adalah kandungan kalsium yang baik untuk pertumbuhan tulang, pada susu kambing hanya tekandung sebanyak 29 gram sedangkan pada susu sapi sebanyak 134 gr.

Tabel. 1. Konsumsi Telur dan Susu Per Kapita dalam Rumah Tangga Tahun 2010 -2014.

\begin{tabular}{lccccc}
\hline \multicolumn{1}{c}{ Uraian } & \multicolumn{5}{c}{ Tahun } \\
\cline { 2 - 6 } & 2010 & 2011 & 2012 & 2013 & 2014 \\
\hline Telur Ayam (Kg) & 6,726 & 6,622 & 6,518 & 6,153 & 6,309 \\
Telur Itik (Butir) & 2,503 & 2,816 & 2,19 & 1,825 & 1,512 \\
Telur Puyuh (Butir) & 2,242 & 2,711 & 3,963 & 3,389 & 3,754 \\
Telur Lainnya (Butir) & 0,156 & 0,156 & 0,156 & 0,104 & 0,156 \\
Susu Murni (Liter) & 0,104 & 0,156 & 0,156 & 0,104 & 0,156 \\
Keju (Ons) & 0,052 & 0,104 & 0,104 & 0,052 & 0,104 \\
Hasil Lain dari Susu (Ons) & 0,365 & 0,365 & 0,417 & 0,209 & 0,313 \\
\hline
\end{tabular}

Sumber : SUSENAS dan BPS 
Hal tersebut membuktikan bahwa susu sapi lebih bagus kandungan nutrisinya dibanding dengan susu kambing.

Meskipun memiliki kandungan nutrisi yang sangat baik bagi tubuh manusia, susu seperti yang kita ketahui termasuk dalam produk pertanian primer yang memiliki karakteristik khusus produk pertanian berbeda dari produk non pertanian yaitu sifatnya yang mudah rusak (perishable), beragam kualitas dan kuantitas (variability), dan memakan ruangan atau bulky (Yudohusodo 2004). Begitu halnya dengan bahan makanan susu, karena karateristiknya yang mudah rusak (perishible) sehingga susu segar yang sudah dibuka dan ditempatkan dalam wadah tanpa mengalami penanganan pasca panen yang bagus hanya akan awet paling lama dua jam. Meskipun dengan penanganan pasca panen yang tepat namun apabila produk susu tersebut belum sampai pada konsumen maka bisa jadi produk tersebut mengalami penurunan kualitas juga. Sehingga diperlukan strategi khusus untuk memasarkan produk tersebut dan salah satunya dengan kegiatan Integrated Marketing Communication.

Tabel. 2. Jumlah Kandungan Gizi yang Terkandung dalam 100 Gr Susu Sapi

\begin{tabular}{lcc}
\hline \multicolumn{1}{c}{ Bahan Kimia } & Susu Kambing & Susu Sapi \\
\hline Protein (g) & 3,3 & 3,6 \\
Lemak (g) & 3,3 & 4,2 \\
Karbohidrat (g) & 4,7 & 4,5 \\
Kalori & 61 & 69 \\
Fosfor (g) & 93 & 111 \\
Kalsium (g) & 29 & 134 \\
Magnesium (mg) & 13 & 14 \\
Besi (mg) & 0,05 & 0,05 \\
Natrium (mg) & 49 & 50 \\
Kalium (mg) & 152 & 204 \\
Vitamin A (IU) & 126 & 185 \\
Thiamin (mg) & 0,04 & 0,05 \\
Riboflavin (mg) & 0,16 & 0,14 \\
Niacin (mg) & 0,08 & 0,28 \\
Vitamin B-6(mg) & 0,04 & 0,05 \\
\hline Sumber: Publikasi
\end{tabular}

Sumber: Publikasi Kementerian Kesehatan

Republik Indonesia

Dewasa ini Indonesia dihadapkan dengan AEC yaitu ASEAN Economic Communityyang akan diarahkan kepada yang paling utama adalah meningkatkan daya saing sektor UMKM. Negara melalui Kementrian
Sekretariat Negara Republik Indonesia (2015) mengatakan bahwa salah satu tantangan AEC 2015 adalah kurangnya daya saing UMKM Indonesia. Oleh karena itu meskipun UMKM kita saat ini sudah memiliki potensi dengan banyaknya produk-produk yang berkualitas, namun apabila tidak diimbangi dengan kegiatan komunikasi yang baik maka hal tersebut akan sia-sia.

Setiadi (2010) mengatakan bahwa betapa pentingnya komunikasi dapat menginformasikan dan membuat konsumen potensial menyadari atas keberadaan produk yang ditawarkan. Sebagai salah satu usaha trendsetter dalam bidang bisnis makanan di Kota Solo, kedai susuMom Milkdinilai sudah memiliki nama yang tidak bisa diabaikan lagi dalam industri di Kota Surakarta. Oleh karena itu peneliti bermaksud untuk mengetahui bagaimana strategi Integrated Marketing Communications yang dilakukan oleh kedai susuMom Milk dalam mempertahankan kegiatan pemasaran dan menarik minat konsumen. Kemudian melalui riset ini akan diketahui kegiatan komunikasi pemasaran kedai susu Mom Milk yang dapat dijadikan sebagai rekomendasi terhadap UMKM yang ada di Indonesia.

\section{METODE PENELITIAN}

Metode dasar yang digunakan dalam penelitian ini adalah metode deskriptif kualitatif mengenai bagaimana proses kegiatan komunikasi pemasaran yang dilakukan oleh Kedai Susu Mom Milk. Menurut Bungin (2007) Metode deskriptif bertujuan untuk menggambarkan dan meringkas berbagai fenomena kemudian menarik ciri, karakter, maupun gambaran tentang fenomena tersebut. Penelitian ini tidak mencari atau menjelaskan hubungan, tidak menguji hipotesis atau membuat prediksi. Penelitian deskriptif melahirkan apa penelitian yang Insight stimulating atau penelitian yang dapat melahirkan wawasan atau pengetahuan.

Teknik penentuan lokasi penelitian yang digunakan adalah secara Purposive dimana teknik tersebut lebih melandaskan diri pada alasan atau pertimbangan-pertimbangan tertentu sesuai dengan tujuan penelitian (Pawito, 2007). Lokasi penelitian yang digunakan oleh peneliti adalah lokasi penelitian 
yang sudah melakukan beberapa kegiatan komunikasi pemasaran atau Integrated Marketing Communications yang terdiri dari Advertisement (periklanan), Promotion Selling (promosi penjualan), Direct Marketing (penjualan langsung), Public Relations (hubungan masyarakat), Personal Selling (penjualan personal), dan Internet Marketing (pmasaran internet). Oleh karena itu, penelitian ini mengambil studi kasus di Mom Milk dengan pertimbangan bahwa Mom Milk sudah menggunakan beberapa kegiatan promosi seperti radio, koran, dan media lainnya.

Penelitian ini menggunakan teknik penentuan informan secara Purposive yang dilakukan dengan menentukan informan dalam wawancara didasarkan pada sumber yang dianggap tepat untuk menjawab pertanyaan yang sudah diajukan oleh peneliti. Kemudian jumlah informan ditentukan dengan Sequential Technique yang menurut Neuman (2006) informan yang dipilih tidak ditentukan batasannya. Jumlahnya terus bertambah dan bertambah sampai peneliti menilai data yang dikumpulkan dari sejumlah informan tersebut telah mencapai titik jenuh. Maksudnya, tidak ada lagi hal baru yang dapat dikembangkan.

Pengembangan validitas data yang digunakan pada penelitian ini menggunakan teknik triangulasi. Triangulasi adalah teknik pemeriksaan keabsahan data yang memanfaatkan sesuatu yang lain di luar data itu untuk keperluan pengecekan atau sebagai pembanding terhadap data itu (Moloeng, 2002).Teknik analisis data dalam penelitian ini menggunakan analisis interaktif. Sutopo (2006) menjelaskan salah satu cara yang dapat digunakan sebagai teknik analisis data dalam penelitian kualitatif ialah mengikuti model analisis interaktif yang terdiri dari 3 komponen pokok yaitu reduksi data, sajian dat, dan penarikan simpulan dengan verifikasinya.

\section{HASIL DAN PEMBAHASAN}

\section{Profil Gambaran Umum Mom Milk}

Mom Milk adalah sebuah industri pengolahan hasil pertanian yang bergerak dalam bidang kuliner. Pemilik dari Kedai Susu Mom Milk adalah Ayudya Putri Fahriana yang biasa dipanggil Putri seorang wanita yang lahir di Bandung 3 Mei 1987. Pada awal berdirinya Kedai Susu Mom Milk adalah sebuah kios susu yang berlokasi di Jl. Menco Raya, kawasan kampus UMS, Gonilan, Kartasura. Alasan Putri mendirikan kios susu adalah memang minuman favorit beliau sejak kecil serta memiliki keinginan agar masyarakat juga menyukai minuman sehat tersebut.

Konsep dari kios susu yang dirintis oleh Putri adalah kafe kecil dengan belasan set meja dan kursi yang diharapkan bisa menjadi tempat para anak muda untuk menghabiskan waktu bersama teman temannya. Hal tersebut dianggap penting karena pasar yang dibidik oleh Putri adalah para mahasiswa dan memang dikawasan tersebut belum ada tempat serupa yang menyediakan susu segar. Berada di lingkungan yang pas membuat usaha ini mendapat respon positif dari para mahasiswa. Berbeda dengan warung susu segar yang hanya menawarkan susu cokelat, jahe atau soda gembira, dia menawarkan rasa susu yang lebih popular di mata anak muda. Sebagaimana kutipan wawancara yang diambil dari Solopos.com "Dulu awalnya saya bikin sembilan rasa, sekarang berkembang menjadi 17 rasa. Dulu ada Cokelat, Vanilla dan sebagainya. Sekarang saya tambah rasa baru seperti durian, hazzlenut, teh Tarik dan sebagainya". Resep rasa susu yang beraneka ragam tersebut adalah resep keluarga yang dibuat langsung oleh ibu dari Putri sejak lama bahkan sejak Putri masih kecil. Meskipun ibu Putri bukan seorang pengusaha susu namun berbekal keahlian dan hasil percobaan sehingga dapat menemukan resep susu tersebut.

Saat ini Mom Milk sudah memiliki limaOutlet di beberapa daerah seperti di Jl. Menco Raya Kawasan Kampus UMS, Jl. Adi Sucipto No. 4 Manahan Solo, Jl. Boulevard Raya, Palem Raya 38 Lippo Karawaci, JL. Muria No. 10 Candi Gajah Mungkur Semarang, JL. Rawa Belong No. 56, Kebon Jeruk, Jakarta Barat. Susu yang diolah di Kedai Susu Mom Milk berbahan baku susu segar yang didatangkan lagsung dari berbagai daerah di sekitar Outlet Mom Milk. Untuk kawasan Solo dan Semarang, susu di datangkan dari daerah Boyolali sementara outlet yang berada di tangerang di datangkan dari Puncak Cisarua Bogor. Sekarang ini terdapat sekitar 20 varian rasa susu di Kedai Susu Mom Milk. Pada hari kerja satu outlet bisa menghabiskan sekitar 80 hingga 100 litersusu sapi segar, sementara pada 


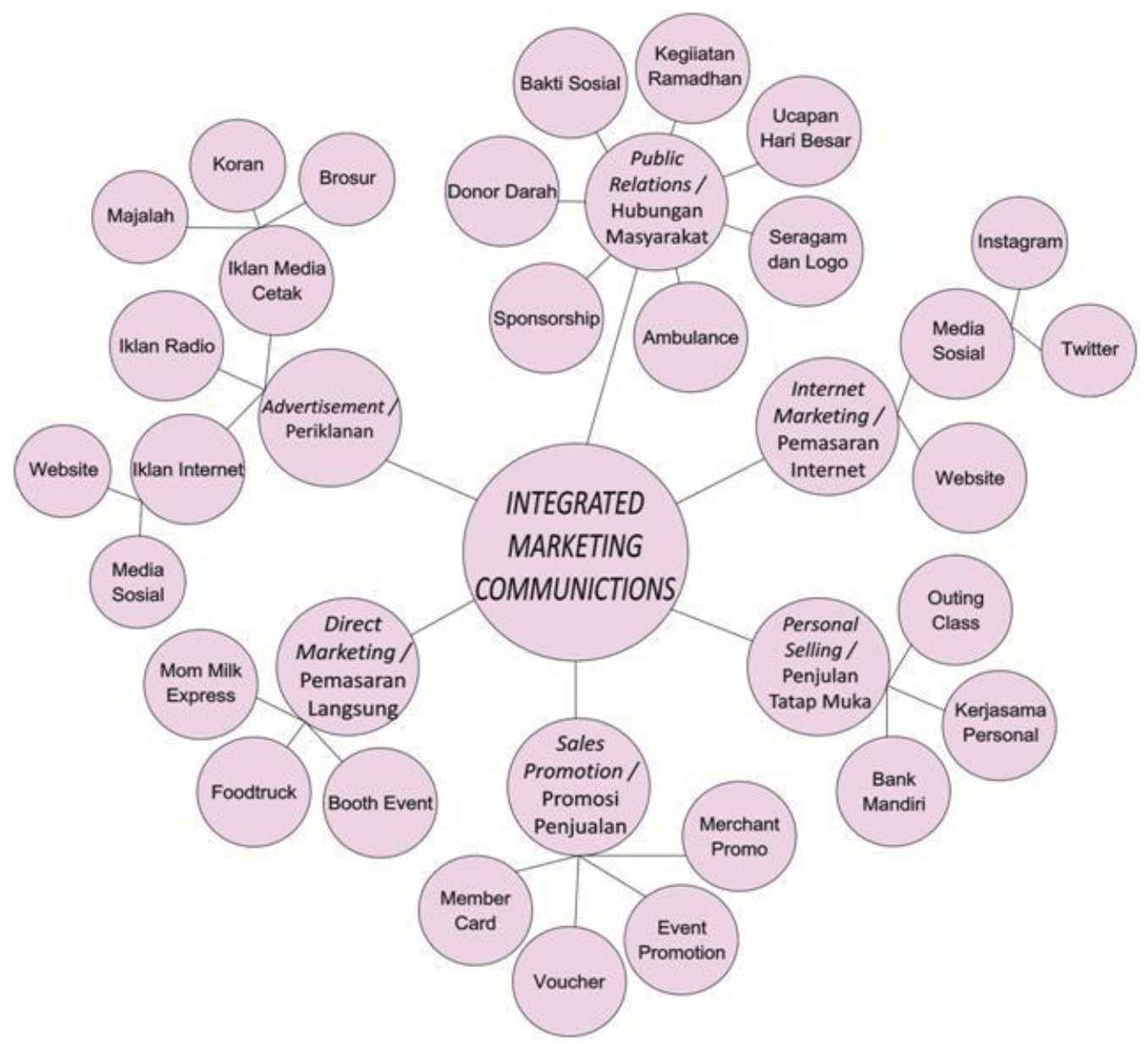

Sumber : Data Analisis Primer dan Sekunder

Gambar 1. Kegiatan Integrated Marketing Communications Mom Milk untuk menarik minat konsumen.

akhir pekan dan hari libur bisa menghabiskan sekitar 100-150 liter susu. Omzet penghasilan tiap outlet bisa mencapai kurang lebih Rp.5.000.000 hingga Rp. 7.000.000 per hari dengan konsumen yang beragam tidak hanya dari kalangan mahasisiwa seperti pada awal dibukanya usaha ini.

Mom Milk memiliki visi untuk menyehatkan masyarakat lewat gerakan minum susu dan ikut meningkatkan pemasaran susu murni dari peternak sapi perah lokal hal tersebut diwujudkan dengan tagline Mom Milk yaitu "Milk for better Health". Visi tersebut kemudian diwujudkan dalam misi dengan menjual produk dengan berbagai macam varian rasa dengan bahan berkualitas nomer 1 di pasaran serta menjadi perusahaan kuliner berbahan baku susu murni dari peternak sapi perah lokal yang beskala nasional.

\section{Aktivitas Integrated Marketing Communications Kedai Susu Mom Milk}

Integrated Marketing Communication atau komunikasi pemasaran terpadu adalah paduan dari berbagai macam bentuk komunikasi pemasaran mulai periklanan, public relation, pemasaran internet, penjualan personal, promosi penjualan dan pemasaran langsung. Hasil penelitian seperti pada gambar 1 adalah bentuk komunikasi pemasaran yang dilakukan oleh Mom Milk dalam menarik minat konsumennya. Masing masing kegiatan memiliki tujuan yang sama yaitu menkomunikasikan Mom Milk baik itu produknya, lokasinya, kegiatannya, dan semua hal tentang Mom Milk untuk menjadikan Mom Milk sebagai sebuah usaha pengolahan hasil pertanian yang memiliki visi untuk menyehatkan masyarakat lewat gerakan minum susu dan ikut meningkatkan pemasaran susu murni dari peternak sapi lokal. Kualitas produk 
dari Mom Milk dijaga dengan mendatangkan bahan baku susu murni berkualitas nomer 1 yang berasal dari daerah peternakan di sekitar outlet Mom Milk. Untuk Mom Milk yang berada di Kota Solo susu didatangkan dari daerah penghasil susu di Boyolali, untuk Mom Milk yang berada di Kota Semarang didatangkan dari daerah Salatiga, sdangkan untuk Mom Milk yang berada di Jakarta didatangkan dari daerah puncak Cisarua Bogor.

\section{Advertising atau Periklanan}

Periklanan adalah komunikasi komersil dan nonpersonal tentang sebuah organisasi dan produk-produknya yang ditransmisikan ke suatu khalayak target melalui media yang bersifat massal seperti televise, radio, Koran, majalah, direct mail (pengeposan langsung), reklame luar ruang, atau kendaraan umum (Lee dan Johnson, 2007).Media periklanan yang digunakan oleh Mom Milk sangat beragam mulai dari periklanan cetak, periklanan siaran, dan periklanan internet. Periklanan cetak Mom Milk menggunakan media cetak majalah dan brosur. Periklanan siaran Mom Milk menggunakan media iklan radio, serta periklanan internet Mom Milk menggunakan sosial media dan website Internet.

a. Periklanan Cetak

Media periklanan cetak yang digunakan oleh Mom Milk adalah menggunakan media cetak majalah (magazines), Koran (Newspaper), Peta wisata, dan brosur. Media cetak digunakan sebagai alat untuk memberikan pengetahuan kepada para konsumen potensial tentang lokasi baru, promosi, atau hanya sekedar menjadi pengingat bagi para konsumennya.

b. Periklanan Radio

Media siaran yang digunakan oleh Mom Milk adalah media radio. Radio telah menjadi bagian integral dalam kehifupan masyarakat. Periklanan media radio yang dilakukan oleh Mom Milk menggunakan stasiun radio Prambors FM dan Soloradio FM, namun dalam 2 tahun terakhir kontrak dengan radio Soloradio FM tidak dilanjutkan karena pertimbangan biaya iklan dan cakupan pendengar radio tersebut.

c. Periklanan Internet

Periklanan internet yang dipakai oleh Mom Milk selama ini menggunakan media sosial
(Twitter dan Instagram). Media sosial digunakan sebagai sarana untuk memberikan informasi secara mendetail dan terus-menerus menggunakan gambar kepada seluruh konsumen potensial dari Mom Milk.

Pesan utama yang disampaikan oleh Mom Milk melalui periklanan adalah memberikan informasi kepada para seluruh pengguna media baik di Solo dan sekitarnya, bahkan di seluruh Indonesia bahwa di Kota Solo terdapat sebuah tempat yang menjual susu segar yang berkualitas dan memiliki varian rasa yang banyak sehingga dapat menjadi daya tarik wisata di Kota Solo. Kemudian secara tidak langsung, Mom Milkjuga memiliki tujuan untuk mengangkat potensi wisata Kota Solo sehingga bisa menjadi salah satu tujuan wisata di Indonesia.

Public Relations atau Hubungan Masyarakat Salah satu yang menjadi variabel komunikasi pemasaran adalah humas atau public relations. Hubungan masyarakat bisa memberikan pengaruh kuat terhadap kesadaran public dengan biaya yang jauh lebih rendah daripada periklanan. (Kotler dan Amstrong 2008).Kegiatan humas yang dilakukan oleh Mom Milk adalah kegiatan yang bersifat sosial yang membantu masyarakat di Kota Solo. Beberapa kegiatan sosial yang pernah dilakukan oleh Mom Milk sebagai bentuk kepedulian sosial adalah kegiatan donor darah, kegiatan bakti sosial, kemudian kegiatan yang khusus pada bulan Ramadhan adalah membagikan takjil atau makanan berbuka puasa kepada masyarakat. Kegiatan tersebut dilakukan sebagai bentuk Coorporate Sosial Responsibility karena Mom Milk sudah menjadi sebuah usaha pengolahan hasil pertanian yang memiliki nama besar di Kota Solo sehingga harus memiliki tanggung jawab sosial agar citra Mom Milk di mata masyarakat bisa terbentuk dengan baik.

Selain melaksanakan kegiatan sosial sebagai bentuk tanggung jawab mereka terhadap lingkungan di sekitar, Mom Milk juga memiliki Ambulance pribadi yang bisa digunakan secara bebas dan tanpa dipungut biaya untuk membantu masyarakat yang membutuhkan kendaraan tersebut. Ambulance tersebut selama ini dikelola oleh Masjid 
Hasyim Al-Hadi Mujahidin iyang berada di daerah Jajar. Bentuk komunikasi yang dilakukan oleh Mom Milk kepada konsumennya adalah melalui logo perusahaan dan seragam karyawan. Seragam karyawan Mom Milk berwarna hitam dengan dengan logo Mom Milk di sebelah kiri, dan Tagline Mom Milk di sebelah kiri.

Logo Mom Milk berbentuk lingkaran dengan tulisan "Mom Milk" berada di tengah lingkaran dan gambar kepala sapi berada di atasnya. Tulisan Mom Milk memiliki arti sebagai identitas utama yaitu sebagai nama perusahaan dan gambar sapi sebagai gambar bahwa susu yang dijual di Mom Milk adalah susu sapi. Logo Mom Milk ini digunakan sebagai identitas utama ketika Mom Milk ikut berpartisipasi sebagai sponsorship dalam sebuah event seperti event kampus, event sekolah, bahkan event Kota Solo.

Internet Marketing atau Pemasaran Internet Sama seperti halnya penyiaran dan cetak, internet juga merupakan salah satu media komunikasi yang bisa menampilkan iklan, memberikan promosi, melakukan kegiatan pemasaran langsung, dan bisa dijadikan sebagai media untuk mengkomunikasikan public relation serta publisitas (Belch and Belch 2001).

Mom Milk menggunakan sosial media instagram dan twitter sebagai media utama untuk promosi online. Mom Milk memiliki cabang di 3 kota dan masing masing outlet Mom Milk menggunakan akun instagram yang berbeda pula. Outlet Mom Milk yang berada di Kota Solo menggunakan akun instagram dengan nama "Mommilk_Solo", outlet Mom Milk yang berada di Semarang menggunakan akun instagram dengan nama "mommilk semarang", sedangkan outlet Mom Milk yang berada di tangerang menggunakan akun instagram dengan nama "mommilk.co". Melalui akun instagram tersebut, Mom Milk memberikan informasi kepada seluruh pengguna sosial media sebagai konsumen potensialnya tentang produk, promo, lokasi, dan bahkan gambaran situasi di dalam Mom Milk melalui foto-foto yang diunggah oleh Mom Milk. Melalui social media ini Mom Milk juga berinteraksi dengan konsumennya melalui kolom komentar yang terdapat pada social media tersebut, sebagaimana dalam Jurnal internasional tentang Evaluating hotel websites as a marketing communication channel : A dialogic perspective(2015) bahwa website dan social media dapat juga digunakan sebagai sarana untuk memberikan layanan jarak jauh serta sebagai alat untuk berdialog dengan para konsumennya.

Bentuk Internet Marketing lainnyayang dimiliki oleh Mom Milk adalah Website dengan alamat websitenya adalah "mommilk.co". Melalui website tersebut Mom Milk memberikan informasi kepada para pengguna internet mengenai produk, lokasi, sejarah, dan visi misi dari Mom Milk. Desain website Mom Milk dibuat sangat menarik dan terkesan lucu dengan menggunakan animasi kartun sebagai hiasan dari website tersebut. Melalui desain yang menarik dan lucu tersebut Mom Milk menunjukkan keunikan dan ciri khas dari Mom Milk yang cocok untuk segala usia dan keluarga yang menjadikan Mom Milk berbeda dengan usaha lainnya.

Direct Marketing atau Pemasaran Langsung Produk yang dijual oleh Mom Milk adalah produk susu yang merupakan produk hasil pertanian yang sudah umum dan sudah banyak dikenal oleh masyarakat luas. Saat ini pelaku usaha sejenis yang mengolah hasil pertanian tersebut sudah banyak berkembang di tengah masyarakat. Salah satu caraMom Milk dalam mengatasi persaingan adalah dengan mendekati konsumen secara langsung. Berdasarkan penelitian, bentuk Direct Marketing yang dilakukan oleh Mom Milk adalah dengan menggunakan Booth dan Foodtruck.

Konsep Direct Marketing yang diterapkan oleh Mom Milk adalah menjual langsung kepada masyarakat yang sedang ramai. Hal tersebut dilakukan sebagai caraMom Milk untuk menjangkau konsumen secara langsung tanpa harus menunggu konsumen tersebut mendatangi Mom Milk di outlet-outlet yang ada. Direct Marketing yang dilakukan oleh Mom Milk adalah salah satu cara untuk menyempurnakan pelayanan public relation dari Mom Milk itu sendiri.

Booth yang digunakan oleh Mom Milk adalah warung kecil yang berisi segala perlengkapan dan aksesoris untuk membuat produk susu olahan mereka. Wujud dari booth Mom Milk adalah seperti sebuah gerobak jual yang tidak memiliki roda dan terbuat dari kayu 
serta berisi peralatan seperti Blender, bahan baku, gelas, dan lainnya. Sedangkan foodtruck milik Mom Milk adalah kendaraan yang memiliki roda namun tidak memiliki mesin dan didalamnya terdapat peralatan yang diperlukan untuk membuat produk olahan susu mereka.

Mom Milk biasanya menggunakan booth untuk event yang periodenya lama seperti pameran, expo, festival, dan event lain yang memiliki periode 3 hari atau lebih. Foodtruck yang dimiliki oleh Mom Milk biasanya digunakan saat Mom Milk ikut berpartisipasi dalam event-event yang periode waktunya hanya sehari saja seperti konser, product launching, dan lainnyaKemudian dari segi penampilan luar, foodtruck lebih menarik dibanding dengan booth karena terlihat lebih simple dan lebih modern.

Meskipun terdapat perbedaan dari segi keuntungan dan kelemahan dari penggunaan booth dan foodtruck, tetapi Mom Milk lebih suka menggunakan booth daripada foodtruck. Hal tersebut karena menurut Mom Milk penggunaan booth meskipun harus dibongkar dan dipasang serta tidak bisa dipindahkan, tetapi booth lebih aman dan lebih mudah untuk digunakan. Penggunaan foodtruck dianggap lebih rumit karena masih harus menggunakan mobil untuk menariknya ke tempat tujuan dan dianggap lebih beresiko untuk membawa peralatan produksi terutama barang elektronik seperti blender. Sedangkan untuk booth tidak perlu mencari mobil untuk menarik booth tersebut karena biasanya di lokasi pameran atau lokasi tempat booth itu akan didirikan sudah disediakan seperti meja atau beberapa perlengkapan lainnya sehingga pihak Mom Milk tinggal membawa perlengkapan tambahan dan aksesoris sebagai hiasan.

Pusat perbelanjaan adalah salah satu lokasi yang sangat potensial bagi seluruh pelaku usaha sebab banyaknya orang yang datang mengunjungi tempat tersebut. Mom Milk memanfaatkan potensi tersebut dengan membuka booth dengan konsep yang berbeda dengan nama "Mom Milk Express". Mom Milk expess ini merupakan salah satu caraMom Milk untuk melakukan pemasaran langsung kepada para konsumen potensial yang berada di pusat perbelanjaan tersebut. Produk yang ditawarkan oleh Mom Milk ekspress sama dengan Mom Milk, namun yang menjadi perbedaanya adalah dari segi pelayanannya. Mom Milk ekspress lebih menekankan kecepatan pelayanan dari pada lokasi yang nyaman untuk bersantai, namun Mom Milk ekspress juga memberikan fasilitas untuk duduk bagi para konsumennya.

\section{Sales Promotion atau Promosi Penjualan}

Belch dan Belch (2001) mengatakan bahwa promosi penjualan adalah rangsangan yang diberikan langsung kepada konsumen yang berupa insentif atau pemberian nilai lebih dari transaksi untuk menciptakan peningkatan penjualan. Insentif atau keuntungan yang diberikan kepada konsumen tersebut bisa berupa potongan harga, voucher, kesempatan mengikuti undian berhadiah, atau mendapatkan produk lebih dari bisanya.Berdasarkan penelitian yang sudah dilakukan, promo yang telah diberikan oleh Mom Milk kepada konsumennya biasanya bertepatan dengan beberapa peristiwa penting baik itu mengenai peringatan hari-hari tertentu, pembukaan outlet baru, serta promo yang bekerja sama dengan beberapa unit bisnis lain.

Promo yang diberikan oleh Mom Milk kepada konsumennya biasanya adalah bentuk potongan harga degan syarat dan ketentuan yang berlaku. Beberapa bentuk promo penjualan yang dilakukan oleh Mom Milk ada yang menggunakan model voucher, potongan harga langsung, dan model merchant promo. Berdasarkan hasil observasi didapatkan data mengenai promo yang diberikan oleh Mom Milk yang bertepatan dengan dibukanya outlet baru Mom Milk yang diberi namaMom Milk express. Pada promo tersebut, Mom Milk memberikan voucher gratis produk pada Mom Milk express beli 2 produk gratis 1 produk denngan minimal transaksi Rp.50.000,00 di Mom Milk outlet manahan.

Promo voucher dalam bentuk "Member Card" juga diberikan oleh Mom Milk kepada para pelanggannya. Setiap pembelian produk Mom Milk yang berada di Mom Milk express, maka konsumen akan mendapatkan member card yang berupa voucher dan dapat ditukarkan dengan produk Mom Milk express lain.Promo penjualanMom Milk juga dilakukan dalam rangka memperingati hari tertentu seperti hasil dari observasi yaitu promo dalam rangka memperingati hari susu nusantara. Mom Milk adalah sebuah usaha yang memiliki produk utama yaitu susu, sehingga Mom Milk memanfaatkan peringatan hari tersebut untuk 
meningkatkan penjualan mereka dengan melakukan promo penjualan potongan $50 \%$ untuk semua minuman. Begitu halnya ketika pemutaran film "Ada Apa Dengan Cinta 2" yang menjadi pembicaraan di kalangan anak muda, sehingga momen tersebut dimanfaatkan oleh Mom Milk dengan memberikan potongan harga 20\% dengan menukarkan tiket film tersebut.

Promo penjualan yang dilakukan Mom Milk juga bekerja sama dengan beberapa unit bisnis lain untuk lebih menarik minat konsumen dalam bentuk merchant promo. Bentuk promo penjualan hasil kerja sama yang dilakukan oleh Mom Milk dengan beberapa unit bisnis lain adalah promo timbal balik antar produk. Konsumen Mom Milkakan mendapatkan potongan harga sebesar $10 \%$ setiap transaksi minimal Rp. 100.000,00 di Mom Milk manahan apabila konsumen tersebut bisa menunjukkan member card dari unit bisnis lain seperti Queen Accesories, Larissa Aesthetic Centre, Aira Skincare, dan El-John.

\section{Personal Selling atau Penjualan Personal}

Belch dan Belch mengatakan bahwa Personal selling involves selling through a person-toperson communications process yang berarti adalah penjualan personal melibatkan komunikasi personal untuk dalam kegiatannya. Hal tersebut bertujuan untuk melakukan penjualan yang membangun hubungan hubungan dengan pelangganya dan menjaga namabaik dari perusahaan tersebut. Namun, peranan dari penjualan personal bervariasi antarperusahaan, bahkan ada beberapa perusahaan yang tidak mempunyai tenaga khusus untuk melakukan kegiatan penjualan personal ini. Mom Milk adalah salah satu usaha yang tidak memiliki tenaga khusus seperti wiraniaga untuk melakukan kegiatan penjualan personal ini.

Mom Milk secara tidak langsung melakukan pendekatan secara personal dengan instansi penting seperti instansi keuangan bahkan instansi pendidikan. Kedekatan Mom Milk dengan intansi penting tersebutlah merupakan modal yang penting untuk Mom Milk agar bisa terus eksis dan bertahan dalam industry pengolahan hasil pertanian seperti ini. Kemudian hasil kegiatan tersebut juga dimasukkan ke dalam koleksi media sosial instagram agar konsumen bisa melihat kegiatan-kegiatan yang dilakukan oleh Mom Milk sehingga harapannya konsumen akan lebih tertarik untuk datang ke Mom Milk.

\section{Hambatan dan Solusi yang dihadapi Kedai Susu Mom Milkdalam menjalankan Strategi Integrated Marketing Communication}

Kegiatan komunikasi pemasaran yang dilakukan oleh setiap pelaku bisnis tidak pernah terlepas dari kondisi yang menjadi hambatan dalam usahanya, begitu pula yang dihadapi oleh usaha Kedai Susu Mom Milk. Mom Milkmemandang bahwa hambatan menjadi tantangan tersendiri untuk lebih mengembangkan usahanya lebih besar lagi. Berdasarkan hasil wawancara dengan narasumber, dapat diketahui informasi bahwa secara umum hambatan yang dihadapi oleh Mom Milkadalah persaingan dan perubahan gaya hidup konsumen.

Semakin banyaknya pelaku usaha sejenis yaitu usaha yang bergerak dalam bidang pengolahan susu segar, mengakibatkan persaingan menjadi sesuatu hal yang tidak bisa dihindarkan dalam bisnis tersebut. Melalui interview dengan supervisor, Mom Milkmenjelaskan bahwa usaha yang mereka kembangkan merupakan satu-satunya usaha pengolahan susu segar dengan varian rasa terbanyak di Kota Solo. Hal tersebut menjadi keunggulan kompetetitif yang dimiliki oleh Mom Milkdalam menghadapi persaingan. Kemudian Mom Milkjuga terus melakukan inovasi baik dari segi produk maupun dari segi tampilannya untuk bertahan di dunia bisnis saat ini.

Hambatan lain yang dihadapi oleh Mom Milk adalah gaya hidup masyarakat modern saat ini. Menurut Mom Milk, saat ini gaya hidup masyarakat sangat mudah berubah ubah mengikuti trend yang ada sekarang. Gaya hidup tersebut tentu akan berdampak kepada selera dan minat konsumen yang menjadikan hal tersebut hambatan sekaligus peluang dalam menjalankan bisnisnya tergantung bagaimana sebuah usaha menyikapinya. Mom Milk selalu berusaha mengikuti trend yang mempengaruhi gaya hidup konsumen dengan aktif di dunia maya dan melakukan riset konsumen. Mom Milk selalu berusaha menarik minat konsumen dengan cara memberikan promo atau insentif penjualan yang berkaitan dengan hal-hal khusus seperti contohnya adalah pemberian 
promo saat peringatan Hari Susu Nusantara, potongan harga saat pemutaran film Ada Apa Dengan Cinta 2, dan potongan harga yang bekerja sama dengan merek dagang lain yang menjadi favorit masyarakat.

\section{KESIMPULAN DAN SARAN}

\section{Kesimpulan}

Kegiatan Komunikasi Pemasaran yang telah dilakukan oleh Mom Milk dalam menarik minat konsumen merupakan strategi yang kreatif dan saling saling terkait antara satu kegiatan dengan kegiatan lainnya. Masing-masing kegiatan tersebut dilakukan dalam rangka menjaga reputasi dan citra Mom Milk dalam dunia bisnis. Advertising dan internet marketing yang dilakukan Mom Milk sebagai cara untuk mempertahankan eksistensinya di masyarakat. Mom Milk juga memanfaatkan event yang ada di Kota Solo melalui kegiatan public relations, direct marketing, dan sales promotion untuk menarik konsumen yang lebih banyak. Kemudian personal selling dilakukan Mom Milk melalui kerjasama dengan unit bisnis lain untuk membuka peluang dalam mengembangkan usahanya.

Hambatan yang ditemui Mom Milk dalam melaksanakan kegiatan komunikasi pemasaran adalah persaingan dan perubahan gaya hidup masyarakat. Semakin banyaknya pelaku usaha di bidang yang sama menyebabkan persaingan tidak dapat dihindari. Mom Milk akhirnya saling berebut konsumen dengan usaha lain untuk bisa bertahan dan berkembang di usaha ini. Kemudian gaya hidup masyarakat yang terus berubah ubah sesuai dengan perkembangan era digital saat ini menuntut gaya komunikasi yang lebih inovatif. Upaya yang dilakukan oleh Mom Milk adalah menambah variasi produk dan menciptakan suasana nyaman sebagai tempat berkumpul bagi para konsumennya. Kemudian Mom Milk terus aktif di media social dengan memasang iklan sebagai pengingat atau memberikan promo promo khusus untuk menarik minat para konsumennya.

\section{Saran}

Setelah melakukan pengamatan dan penelitian mengenai kegiatan Integrated Marketing Communication (IMC) atau komunikasi pemasaran terpadu yang dilakukan oleh Mom
Milk, maka ada beberapa saran yang bisa diberikan peneliti adalah sebagai berikut :

1. Mom Milk merupakan usaha pengolahan hasil pertanian yaitu susu yang sudah memiliki nama besar di Kota Solo namun dari pengamatan peneliti ada beberapa peluang usaha yang belum dimanfaatkan secara maksimal. Peluang tersebut diantaranya adalah Mom Milk bisa menjadi supplier minuman bagi beberapa usaha kuliner terkenal di Kota Solo seperti halnya minuman PEPSI yang menjadi supplier minuman bagi $K F C$. Kegiatan komunikasi Personal Selling bisa lebih dimaksimalkan lagi dengan bekerja sama dengan beberapa unit bisnis yang bergerak di bidang makanan tersebut, sehingga Mom Milk bisa menjadi supplier minuman Susu dari usaha makanan tertentu.

2. Mom Milk dan usaha bisnis lain harus melakukan riset konsumen mengenai kebutuhan, selera, preferensi, dan gaya hidup karena saat ini gaya hidup masyarakat semakin berkembang dan cepat mengalami perubahan. Hal ini dilakukan agar Mom Milk dan usaha bisnis lain tersebut dapat memenuhi kebutuhan masyarakat sehingga dapat bertahan di dunia bisnis seperti saat ini.

3. Pemerintah diharapkan lebih memperhatikan dan mendukung perkembangan unit-unit usaha yang memiliki potensi besar seperti Mom Milk yang mungkin bisa menjadi keunggulan komparatif daerah dibandingkan dengan daerah lain. Sehingga di setiap daerah di Indonesia nantinya mempunyai unit-unit usaha unggulannya masing-masing untuk menyongsong eksistensi Indonesia di Asean Economic Community

\section{DAFTAR PUSTAKA}

Alifahmi, Hifni. 2008. Marketing Communications Orchestra. Bandung: Examedia Publishing.

Belch, George E. and Michael A. Belch. 2001. Advertising and Promotion : an integrated Marketing Communications Perspective. 5th edition. The McGrawHill Companies, inc. New York. 
Firsto Rozi K., Setyowati, Hanifah I. : Strategi Integrated Marketing Communication (IMC)...

Bungin, Burhan. 2007. Penelitian Kualitatif : Komunikasi, Ekonomi, Kebijakan Publik, dan Ilmu Sosial Lainnya. Kencana Prenada Media Group. Jakarta

Ibrahim, Masud 2015. Evaluating Hotel Websites as a Marketing Communication Channel : A Dialogic Perspective. Information Development Journal 32: $718-727$

Kotler, Phillip and Gary Amstrong. 2008 Principles of Marketing, 12 edition. Pearson Education, inc

Lee, Monle and Carla Johnson.1999. Principles of Advertising : A Global Perspective. The Haworth Press

Moeloeng, Lexy. 2002. Metodologi Penelitian Kualitatif.Bandung : PT Remaja Rosdakrya
Neuman, W. Lawwrence. 2006. Social Research Methods : Qualitative and Quantitative Approaches. Michigan : Pearson - University Of Michigan

Pawito. 2007. Penelitian Komunikasi Kualitatif. Jogjakarta : LKiS

Sangadji, Etta Eamang dan Sopiah. 2013. Perilaku Konsumen : Pendekatan Praktis. Yogyakarta : Andi Offset.

Siswono Yudo Husodo, dkk. 2004. Pertanian Mandiri "Pandangan Strategis Para Pakar Untuk Kemajuan Pertanian Indonesia. Bogor : Penebar Swadaya

Sutopo, HB. 2006. Metodologi Penelitian Kualitatif : Dasar Teori dan Terapannya Dalam Penelitian. UNS Press. Surakarta. 